\title{
Pyrazinamide Effects on Cartilage Type II Collagen Amino Acid Composition
}

\author{
Larysa B. Bondarenko and Valentina M. Kovalenko \\ SI "Institute of Pharmacology and Toxicology" National Academy of Medical Sciences of Ukraine, \\ Eugene Potier 14, 03680 Kyiv, Ukraine
}

Correspondence should be addressed to Larysa B. Bondarenko, larabon04@yahoo.com

Received 5 December 2011; Revised 13 February 2012; Accepted 16 February 2012

Academic Editor: Katsuhiro Konno

Copyright ( 92012 L. B. Bondarenko and V. M. Kovalenko. This is an open access article distributed under the Creative Commons Attribution License, which permits unrestricted use, distribution, and reproduction in any medium, provided the original work is properly cited.

\begin{abstract}
Introduction. Current therapeutic regimens with first-line antitubercular agents are associated to a high rate of adverse effects which could cause pronounced changes in collagen's contents and structure. Investigation of these changes is very important for optimization of antitubercular therapy and minimization of treatment-caused harm. The aim of present paper was to investigate potential effect of pyrazinamide on male rats' cartilage type II collagen amino acid composition. Materials and Methods. Wistar albino male rats (160-200 g b.w.) were divided into three groups: I-received pyrazinamide per os at a dose of $1000 \mathrm{mg} / \mathrm{kg}$ b.w./day; II-at a dose of $2000 \mathrm{mg} / \mathrm{kg}$ b.w./day, in both groups it was given for 60 days; III-control. After 60 days of the experiment, rats of the experimental (groups I and II) and control groups were sacrificed and the amino acids contents of male rat cartilage type II collagens were determined using amino acid analyzer. Results and Discussion. The study of pyrazinamide effects (administered in different doses) on rat cartilage type II collagen amino acid contents demonstrated presence of dose-dependent pyrazinamidemediated quantitative and qualitative changes in these rat extracellular matrix proteins in comparison with control.
\end{abstract}

\section{Introduction}

There has been resurgence in tuberculosis worldwide. Approximately 2 billion people have latent infection, 8 million would develop active tuberculosis annually, and 2-3 million would die due to tuberculosis. With this resurgence, cases with extrapulmonary tuberculosis have also shown an increase. Approximately $10-11 \%$ of extrapulmonary tuberculosis involves joints and bones, which is approximately 1$3 \%$ of all tuberculosis cases. The global prevalence of latent joint and bone tuberculosis is approximately 19-38 million cases [1].

Collagens are major structural proteins of the extracellular matrix, joints, and bones and their correct structure is crucial for the proper functioning of locomotor apparatus. Both tuberculosis per se and its chemotherapy with antitubercular drugs could cause pronounced changes in collagen's contents and structure $[1,2]$. Investigation of these changes is very important for improving first-line antitubercular therapy and minimization of its adverse effects.
Previously we have demonstrated putative changes in rat bone and skin type I collagens amino acid contents with using different doses of pyrazinamide [2, 3]. Type II collagen has been classically recognized as the major collagenous component of cartilage.

The aim of present study was to investigate potential effect of pyrazinamide on male rats cartilage type II collagen amino acid composition.

\section{Materials and Methods}

Cartilage type II collagens were extracted and purified according to Trelstad et al. [4]. All procedures were carried out at $4^{\circ} \mathrm{C}$. Cartilages $(20 \mathrm{~g})$ were grinded. Extraction of proteoglycans was carried out by $100 \mathrm{~mL} 2 \mathrm{M} \mathrm{MgCl}_{2}, 0.05 \mathrm{M}$ Tris (pH 7.6) during 3 days. Extract was decanted. Cartilages were washed by distilled water (3 times). Collagen was extracted by $100 \mathrm{~mL} 0.1 \mathrm{M}$ acetic acid ( $\mathrm{pH}$ 2.5) with pepsin. Pepsin $(20 \mathrm{mg} / \mathrm{g}$ of tissue) was added into this solution and mixtures were left for 3 days in refrigerator at $4^{\circ} \mathrm{C}$. 
TABLE 1: Male rats cartilage type II collagen amino acid contents in control and with pyrazinamide administration at doses $1000 \mathrm{mg} / \mathrm{kg}$ and $2000 \mathrm{mg} / \mathrm{kg}$ of body weight ( $\mathrm{M} \pm \mathrm{m}, n=5$, residues/1000 residues).

\begin{tabular}{|c|c|c|c|}
\hline Amino acid & Control (norm) & Pyrazinamide $1000 \mathrm{mg} / \mathrm{kg}$ & Pyrazinamide $2000 \mathrm{mg} / \mathrm{kg}$ \\
\hline Hydroxylysine & $5.60 \pm 1.20$ & $4.20 \pm 0.80$ & $3.50 \pm 0.40$ \\
\hline Lysine & $29.9 \pm 1.80$ & $31.80 \pm 2.70$ & $33.30 \pm 2.50$ \\
\hline Histidine & $8.30 \pm 1.20$ & $7.10 \pm 1.30$ & $5.60 \pm 0.30$ \\
\hline Arginine & $53.83 \pm 3.35$ & $53.00 \pm 5.80$ & $39.90 \pm 3.00^{* \#}$ \\
\hline Hydroxyproline & $95.80 \pm 2.70$ & $91.70 \pm 4.70$ & $85.90 \pm 2.90$ \\
\hline Aspartic acid & $53.50 \pm 5.10$ & $62.30 \pm 6.40$ & $72.10 \pm 10.60$ \\
\hline Threonine & $29.80 \pm 6.60$ & $29.20 \pm 1.30$ & $33.70 \pm 2.10$ \\
\hline Serine & $34.00 \pm 1.98$ & $49.80 \pm 1.60^{*}$ & $56.30 \pm 2.30^{* \#}$ \\
\hline Glutamic acid & $88.10 \pm 3.47$ & $115.40 \pm 6.30^{*}$ & $110.80 \pm 12.20^{*}$ \\
\hline Proline & $91.70 \pm 1.60$ & $91.20 \pm 4.10$ & $86.10 \pm 3.70$ \\
\hline Glycine & $310.20 \pm 7.70$ & $282.10 \pm 9.90$ & $294.00 \pm 6.40$ \\
\hline Alanine & $105.62 \pm 2.78$ & $92.60 \pm 1.80^{*}$ & $72.10 \pm 5.50^{* \#}$ \\
\hline Valine & $24.80 \pm 1.89$ & $16.70 \pm 3.60^{*}$ & $32.90 \pm 1.57^{* \#}$ \\
\hline Methionine & $7.60 \pm 1.50$ & $3.80 \pm 1.00$ & $2.70 \pm 0.70$ \\
\hline Isoleucine & $13.35 \pm 0.79$ & $8.30 \pm 0.80^{*}$ & $10.60 \pm 1.80$ \\
\hline Leucine & $23.43 \pm 1.85$ & $34.30 \pm 2.00^{*}$ & $32.90 \pm 1.00^{*}$ \\
\hline Tyrosine & $7.30 \pm 0.80$ & $6.80 \pm 0.30$ & $7.50 \pm 0.50$ \\
\hline Phenylalanine & $18.80 \pm 0.80$ & $20.80 \pm 2.30$ & $20.60 \pm 2.10$ \\
\hline
\end{tabular}

$\mathrm{M} \pm \mathrm{m}$ : mean \pm mean standard error.

${ }^{*} P<0.05$ statistically significant in comparison with control.

${ }^{\#} P<0.05$ statistically significant pyrazinamide, $1000 \mathrm{mg} / \mathrm{kg}$ group versus pyrazinamide, $2000 \mathrm{mg} / \mathrm{kg}$ group.

After that for pepsin inactivation $\mathrm{pH}$ in each mixture was neutralized by addition of powdered crystalline Tris (to $\mathrm{pH}$ 7.6). Solutions were centrifuged: $35000 \mathrm{~g}, 40 \mathrm{~min}$, $4{ }^{\circ} \mathrm{C}$. Pellets were discarded and supernatants were used for further collagen types fractionation. Fractionation of pure type II collagens was carried out by growing concentrations of $\mathrm{NaCl}$ according to method [4]. Protein fraction from pellet which was formed at $4.4 \mathrm{M} \mathrm{NaCl}$ concentration contained type II collagen. Fractions were separated by centrifugation $\left(65000 \mathrm{~g}, 60 \mathrm{~min}\right.$, at $\left.4^{\circ} \mathrm{C}\right)$. Obtained pellets were recrystallized ( 3 times) by dialysis (against $15 \% \mathrm{KCl}$ in $0.02 \mathrm{M} \mathrm{NaHPO}_{4}$ at $4^{\circ} \mathrm{C}$ ) and centrifugation (65000 g, $60 \mathrm{~min}$, at $4^{\circ} \mathrm{C}$ ) [5]. Collagen preparations purity was controlled electrophoretically [6].

Collagen fractions were hydrolyzed: $24 \mathrm{~h}, 6 \mathrm{~N} \mathrm{HCl}, 105^{\circ} \mathrm{C}$ [7]. Their amino acid compositions were analyzed by ion exchange chromatography on the amino acid analyzer AAA881 (Czech Republic).

In statistical processing of experimental data mean of corresponding parameter (for each animal) was used as independent variable. The obtained data were calculated by one-way analysis of variance (ANOVA). Data were compared using Tukey test. Differences were considered to be statistically significant at $P<0.05$.

\section{Results and Discussion}

Changes in male rat cartilage type II collagen amino acid contents induced by pyrazinamide were profound as compared to control (Table 1). Statistically significant changes were registered in cartilage collagen with pyrazinamide administration at dose $1000 \mathrm{mg} / \mathrm{kg}$ for 6 amino acids and at dose $2000 \mathrm{mg} / \mathrm{kg}$ for 6 amino acids.

Cartilage type II collagen of male rats with pyrazinamide at dose $1000 \mathrm{mg} / \mathrm{kg}$ contains lower contents of alanine $(-12.3 \%)$ and isoleucine $(-37.8 \%)$ simultaneously with higher contents of serine $(+46.5 \%)$, glutamic acid $(+31.0 \%)$, and leucine $(+46.6 \%)$. Collagen of rats with pyrazinamide at dose $2000 \mathrm{mg} / \mathrm{kg}$ contains lower contents of arginine $(-25.9 \%)$ and alanine $(-31.7 \%)$ simultaneously with higher contents of serine $(+65.6 \%)$, valine $(+32.7 \%)$, and leucine $(+40.6 \%)$. For the majority of amino acids pyrazinamide effects were dose dependent.

Our experiments demonstrated presence of qualitative changes in male rats' cartilage type II collagens with pyrazinamide (in comparison with norm) (Table 1). With pyrazinamide administration possibly could be formed cartilage type II collagen molecules with changed surface charge (changes in number of arginine, serine, and glutamic acid residues), rigidity (changes in quantity of alanine, valine, isoleucine residues), number of specific loci responsible for cell adhesion, interaction with chaperons, and procollagen processing to collagen (changes in arginine residues) [814]. Such collagen molecules changes could hence affect the properties of connective tissues, mineralisation processes, and calcium metabolism.

Comparative analysis of present results with our previous data on skin and bone type I collagens demonstrated analogous character of changes in regard to contents of serine, glutamic acid, alanine, valine, and leucine residues $[2,3]$. This could be the evidence of existence some general mechanisms of pyrazinamide effects on collagen's contents 
and structure. Moreover, having compared these data with our previous experiments, we found out analogous character of these changes in regard to changes of free serine, glutamic acid, alanine, valine, and leucine contents in liver, kidney, lung and spleen pools with different doses of pyrazinamide [8]. Thus adverse effects of pyrazinamide (this widely used antitubercular drug) are much more serious and more profound than it was considered earlier. Among this pyrazinamide treatment could cause qualitative changes in nucleic acid molecules, change their length, and structure [9].

We can suppose that such changes could be caused by pyrazinamide via its influence on nucleic acids (coding information for this proteins synthesis) as it was mentioned previously $[2,9,10]$. In our previous experiments we demonstrated epigenetic changes induced by pyrazinamide treatment, pyrazinamide-mediated alterations in male rats DNA fragmentation processes, bone type I collagen amino acid composition, spermatogenesis indices, reproductive capability, and posterity antenatal and postnatal development. Besides these, on changes in collagen metabolism and structure pathologic changes in amino acid metabolism could also be affected [8]. And at last, due to collagen genes polymorphism [11-14], collagen structures contain in norm 4 different $\alpha$-chains of the same type in different concentrations. Pathology [14] changed concentrations in which these 4 different $\alpha$-chains of the same type of collagen are present in connective tissue structures. Possibly pyrazinamide-caused disturbances in amino acid compositions in our experiments could be a result of such changes in transcription rates of genes coding different $\alpha$-chains from the same type collagen superfamily as it was previously demonstrated for other pathology [14].

\section{References}

[1] A. N. Malaviya and P. P. Kotwal, "Arthritis associated with tuberculosis," Best Practice and Research, vol. 17, no. 2, pp. 319-343, 2003.

[2] L. B. Bondarenko, G. M. Shayakhmetova, T. F. Byshovets, and V. M. Kovalenko, "Pyrazinamide-mediated changes in rat type I collagen and spermatogenesis indices," Acta Poloniae Pharmaceutica-Drug Research, vol. 68, no. 2, pp. 285-290, 2011.

[3] L. B. Bondarenko, G. M. Shayakhmetova, T. F. Byshovets, and V. M. Kovalenko, Acta Poloniae Pharmaceutica. In press.

[4] R. L. Trelstad, V. M. Catanese, and D. F. Rubin, "Collagen fractionation: separation of native types I,II and III by differential precipitation," Analytical Biochemistry, vol. 71, no. 1, pp. 114-118, 1976.

[5] A. L. Rubin, M. P. Drake, P. F. Davison, D. Pfahl, P. T. Speakman, and F. O. Schmitt, "Effects of pepsin treatment on the interaction properties of tropocollagen macromolecules," Biochemistry, vol. 4, no. 2, pp. 181-190, 1965.

[6] G. Maurer, in The Disk-Electrophoresis, p. 247, Mir, Moscow, Russia, 1971.

[7] T. Deveni and J. Gherghey, in The Aminoacids, Peptides and Proteins, p. 364, Mir, Moscow, Russia, 1976.
[8] L. B. Bondarenko, N. A. Saprykina, and V. M. Kovalenko, "Lung and spleen contents of free amino acids after pyrazinamide treatment," Acta Toxicologica, vol. 14, no. 1-2, pp. 7986, 2006.

[9] V. M. Kovalenko, T. V. Bagnyukova, O. V. Sergienko et al., "Epigenetic changes in the rat livers induced by pyrazinamide treatment," Toxicology and Applied Pharmacology, vol. 225, no. 3, pp. 293-299, 2007.

[10] L. Bondarenko, G. Shayakhmetova, T. Byshovets, and V. Kovalenko, International Journal of Infectious Diseases, vol. 15, supplement S99, 2011.

[11] S. R. Kimball, M. Yancisin, R. L. Horetsky, and L. S. Jefferson, "Translational and pretranslational regulation of protein synthesis by amino acid availability in primary cultures of rat hepatocytes," International Journal of Biochemistry and Cell Biology, vol. 28, no. 3, pp. 285-294, 1996.

[12] J. Inamasu, B. H. Guiot, and D. C. Sachs, "Ossification of the posterior longitudinal ligament: an update on its biology, epidemiology, and natural history," Neurosurgery, vol. 58, no. 6, pp. 1027-1038, 2006.

[13] J. D. Kurt, S. Makoto, K. Tomoatsu, and Y. Yoshihiko, "Complete coding sequence and deduced primary structure of the human cartilage large aggregating proteoglycan, aggrecan," The Journal of Biological Chemistry, vol. 266, no. 2, pp. 894902, 1991.

[14] B. Lee, M. D’Alessio, H. Vissing, F. Ramirez, B. Steinmann, and A. Superti-Furga, "Characterization of a large deletion associated with a polymorphic block of repeated dinucleotides in the type III procollagen gene (COL3AI) of a patient with Ehlers-Danlos syndrome type IV," American Journal of Human Genetics, vol. 48, no. 3, pp. 511-517, 1991. 

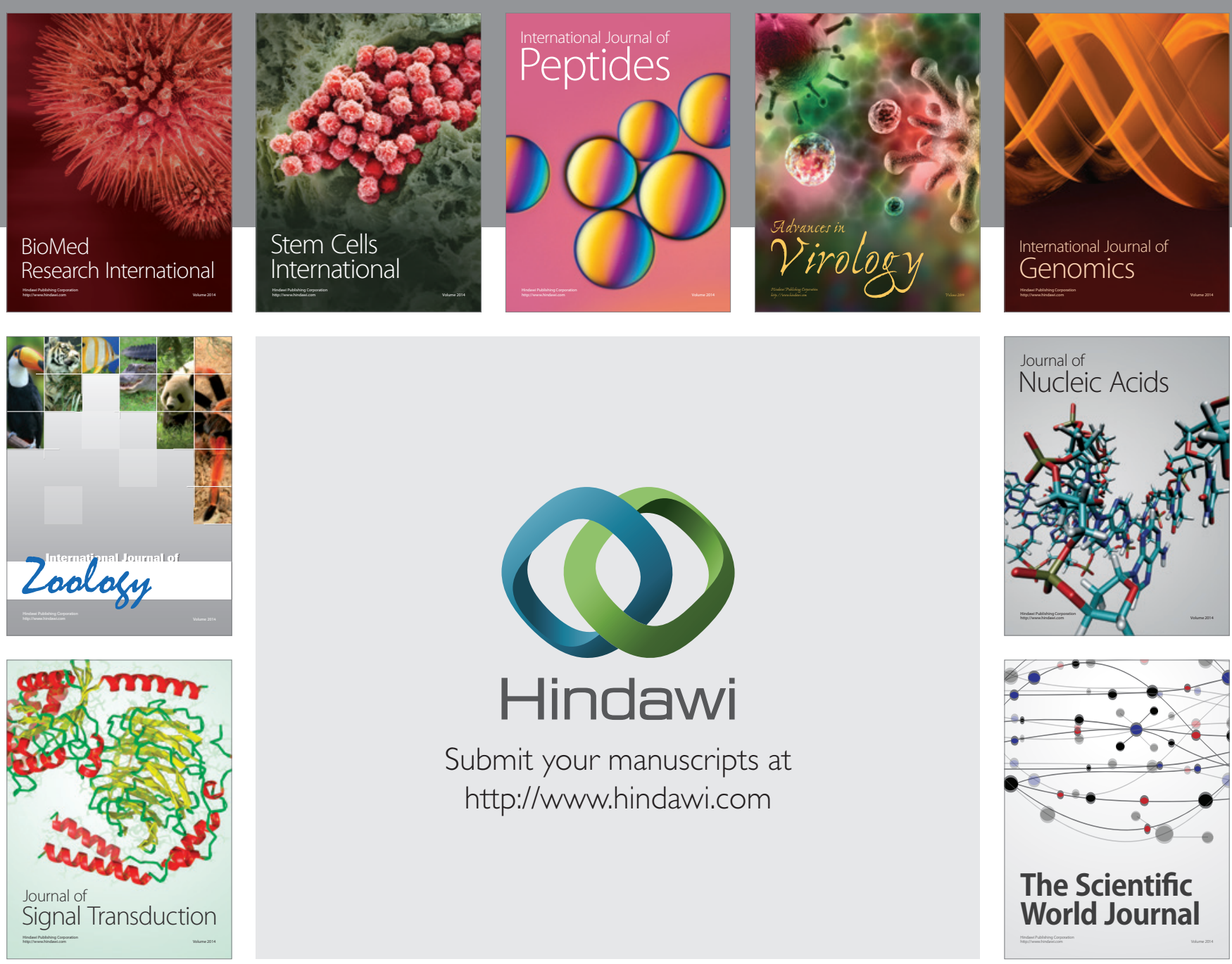

Submit your manuscripts at

http://www.hindawi.com
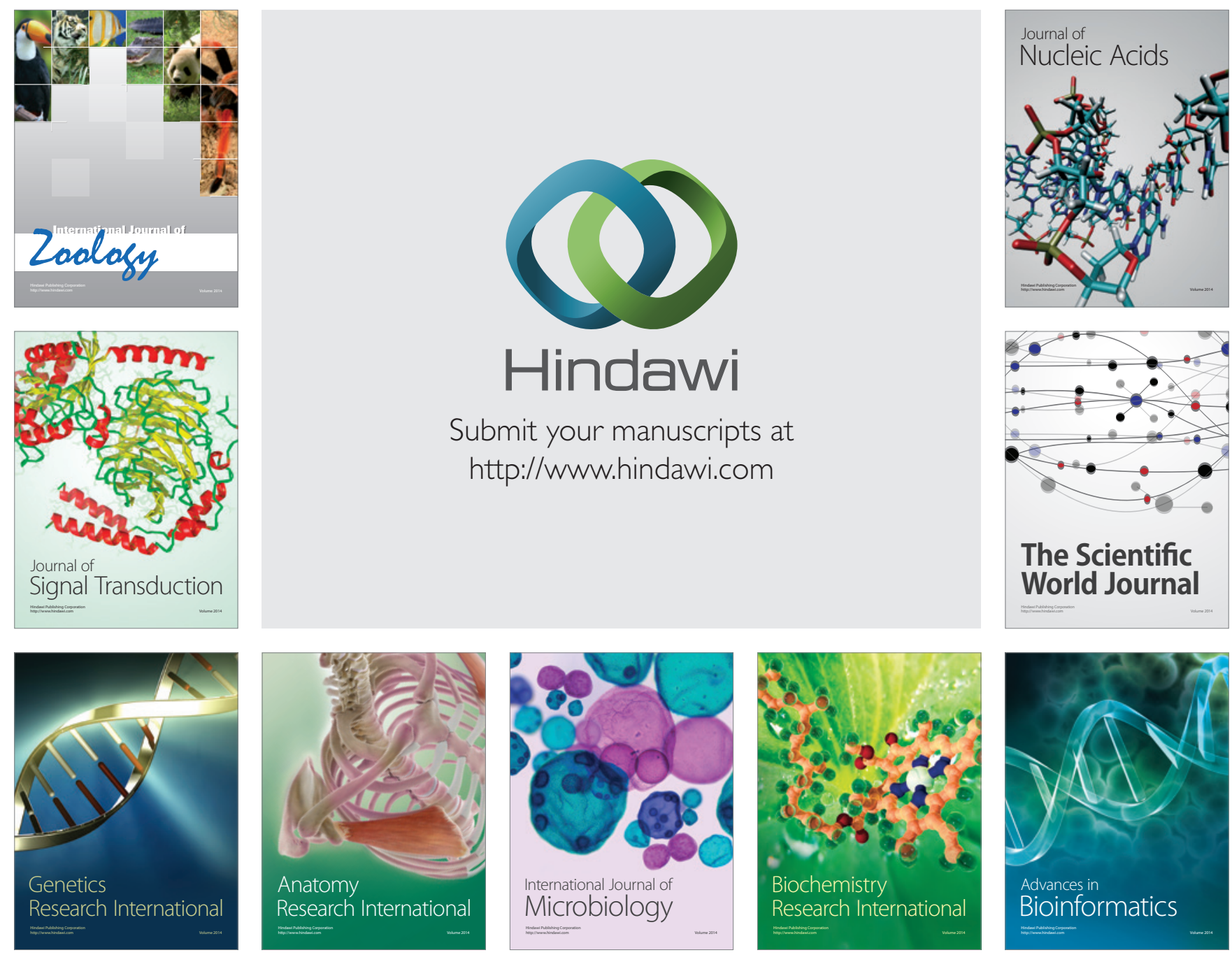

The Scientific World Journal
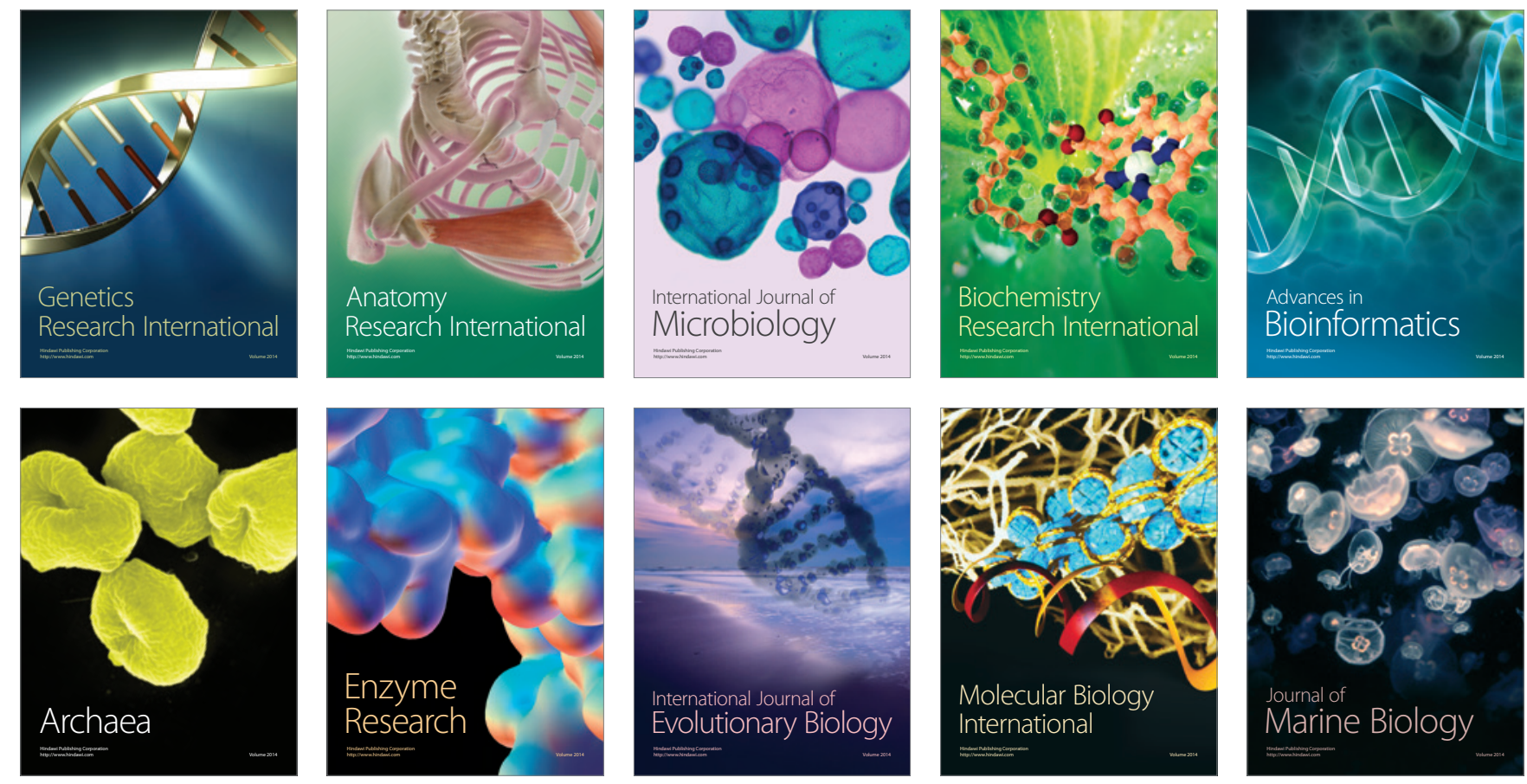